\title{
信息化技术与中职英语课程整合的问题与对策
}

\author{
季聪聪 \\ 天津市经济贸易学校 \\ DOI:10.32629/er.v1i4.1538
}

[摘 要] 随着信息技术的发展,信息化教学已成为一种重要的教学方式。信息化教学的理论与实践已渐趋丰富,技术手段也日 渐多元化。目前研究关注的重点已由重视硬软件及资源建设,转为关注信息化技术在学校和课堂中应用的有效性,即信息化教 学的效果、效率和效益。本文就如何实现信息化技术与中职英语课程的有效整合及相应的对策发表了一定的看法。

[关键词] 信息化; 中职英语; 整合; 对策

\section{1 现代信息技术与中职英语教学有效整合的内涵}

信息技术与中职英语教学有效整合是指针对中职生活 泼好动, 不爱学, 学不会或不会学的学习特点, 将信息技术有 机地融和在中职英语课程教学过程中, 把信息技术、信息资 源信息方法和中职英语课程的课程结构、课程内容、课程资 源以及课程实施等融合为一体, 有机结合, 以便更好地完成 课程目标, 以提高教与学的效率, 改善教与学的效果, 改变传 统的教学模式, 更好完成课程教学任务的一种新型的教学方 式。

\section{2 目前信息技术与中职英语教学整合的特征、问题与解} 决策略

2.1 信息技术在中职英语课程中的功能

(1) 激发学生兴趣, 创设真实情境

通过真实的情景, 动感的画面, 富于情感的对话交流, 创设视听一体的教学环境, 缩短了学生与陌生事物间的距 离, 增强了形象的真实感, 引起了学生的注意, 激发了他们 的好奇心和表演欲, 有利于调动学生的学习兴趣, 从而吸引 学生积极性, 主动地参与到语言实践活动中来, 使学习的过 程生动真实, 学习氛围轻松快乐。此外利用信息技术辅助英 语教学, 可以降低难度、突破难点, 可以将一些原本抽象、 晦涩难懂的内容用生动、具体、形象的侧面展示出来, 达到 易懂的效果。例如, 学习有关天气的相关词汇和句型时, 我 先播放一段有关天气的视频, 为学生创设情景, 形象的了解 “sunny, windy, cloudy, rainy” 的具体词汇的含义, 进而讲 解询问天气的方式: How is the weather?或 What is the weather like? 与传统教学的课本、录音机相比, 多媒体计 算机提供了更为真实、更接近自然规律的语言输入。这是 任何其它媒体所不能替代的一种方式, 它能有效地激发学 生的学习兴趣, 使学生产生强烈的学习欲望, 从而形成学习 动机, 并逐步培养和提高利用信息技术寻找和学习新知识 的能力。

(2) 信息技术的应用有利于增大教学容量, 提高学习效 率; 优化课堂结构, 突出重点, 突破难点。现代教育技术还可 以超越时空, 把教学内容及其延伸情景生动。逼真地再现眼 前, 使抽象的知识变得具体化、简单化、直观化、缩短了客
观实物与学生之间的距离。从而降低了难度, 使学生容易接 受和理解, 获得更为深刻, 清晰的感知。

(3) 信息技术的应用有利于扩充学习资源, 拓展合作 交流的渠道, 培养学生良好的语感和语言交际能力。中职 生英语水平差, 但他们对社会的热点, 国外的文化还是有 一定的兴趣的。网上可以提供大量的阅读材料以及与课文 相关的背景资料, 增大学生英语语言的输入量, 培养学生 良好的语感, 同时可以使学生开阔视野, 了解外国的文化。 例如, 在学生学习语言交际词语时, 教师可以向学生提供 交际活动的文化背景, 把语言和形象联系起来, 通过多种 感官来获取大量的信息知识, 让学生通过对这些情境的探 究、发现和研究来加强对学习内容的理解, 对外国的社会 环境、风俗习惯、民族心理进行探索和发现, 培养学生的 探索精神和创新能力。

（4）信息技术的应用有利于促进个性化学习, 为学生 创造自主学习的条件, 培养学生的探究意识和创新能力。 中职生中也不乏对口与提高很感兴趣的学生, 手机已很普 遍, 就此可以让学生尝试使用有利于提高口语的相关手机 app 等软件, 教师可以在线查看学生的学习效果, 有针对性 进行指导。而知识数据库的学习, 需要学生主动思考, 归 纳、总结、探索英语学习的规律, 进而也就培养了学生的 探究意识。

2.2 多媒体运用于英语教学的主要问题与解决的对策

虽然现代信息技术与课程的整合给我们的教育带来了 翻天覆地的变化, 但在实际的运用过程中始终存在很多问 题。

（1）要注意避免过度使用多媒体教学。学生上课时眼睛 长时间盯着大屏幕, 刺激时间过长, 容易造成学生视觉疲倦, 从而影响视力下降。尤其是中职生, 精力也不容易集中。因 此在教学过程中, 英语教师应当重视教学系统设计, 与其他 教学手段相结合, 高效益地应用信息技术来进行课堂教学。 如小组讨论、前台展示、表演等多样式的教学手段更适合与 中职生。教师不应一味赶潮流, 而应根据学生的学习特点, 教学的需要和自身的教学风格选择合适的媒体和手段, 发挥 其各自的长处而不要过多关注技术应用的多少和技术是否 
精美, 为了信息化而信息化。

(2) 网络多媒体的在教学中频繁的使用淡化了师生之间 交流和互动。教师必须在教学过程中操作多媒体, 这也就导 致了学生在学习过程中容易过度专注于多媒体课件, 而对教 师的表情与肢体语言开始忽略, 进而淡化了师生间的交流和 互动。而我们知道英语教学是一个师生情感交流的过程, 信 息技术不可代替教师在课堂上的引导、启发、鼓励、或批评。 英语是活生生的语言, 只有承载了交流信息和情感才能变得 生动、被人理解。所以, 英语课堂上老师可利用信息化手段 创设情境, 开展双人对话、小组对话、辩论、角色扮演、故 等拓展性活动, 从而为学生提供充分的表达和交流的机会, 有助于提高其语言的综合运用能力。

(3) 充分发挥教师的主导地位。在现实生活中, 许多教师 过分热衷信息技术, 没有很好地领会信息技术用于英语教学 的实质。在英语教学中过分依赖信息技术, 变信息技术辅助 教学为信息技术主导教学, 盲目地依赖信息技术手段把所有 的教学环节再现出来, 在教学中教师成了信息技术的奴隶。 教师只起到了操作员和解说员的作用, 而没起到教师应有的 主导作用。甚至有人认为计算机与网络已经提供了那么多英 语信息和资源, 教师只要在课堂上展示和共享这些内容或为 学生提供足够的线索就可以了。这其实都是一种误解。实际 上, 无论是学生的自主学习还是合作学习, 无论是利用信息 技术进行教学还是传统教学, 都离不开教师的指导。教师在 英语教学中依然担当重要的角色。教师的主导作用首先体现 在帮助学生寻找合适的学习资源并指导学生使用。尤其是中 职生自身的知识能力有限, 判断能力不够, 需要教师认真示 范, 知道才能正确使用网络进行学习。

其次在信息技术环境下教师应加强对学习任务的明确 示范和指导。教师应使学生明确每一个教学活动的目的,
调节他们的注意力, 并注意及时的反馈矫正, 以恰到好处地 发挥教师自身的主导作用和多媒体的辅助作用。例如组织 中职学生在进行小组合作学习时, 教师应在组际间巡回指 导, 因为中职生的自我约束能力较差, 利用电脑的 “监控” 功能, 观察学生的屏幕, 了解他们操作的内容, 学习程度, 否 则学生可能会悄悄玩上游戏; 练习回答情况; 通过电脑的 “交互辅导” 功能对学生 “电子举手” 提出的疑难进行个 别解答或对个别学生提示学习方法, 为他们的自主学习引 导方向。

总而言之, 信息技术应用于中职英语教学不仅是教学 手段的改进, 更重要的是它对教育教学观念产生了巨大冲 击。当然, 信息技术与中职英语的整合教学并非是常规教学 的全部, 也不是每课都适宜使用, 需要根据学生的专业, 以 及学习特点进行教学设计, 根据教学目标来更有效地把多 媒体和网络技术应用于教学之中。在中职英语课堂教学中, 恰当、巧妙地利用现代教学媒体辅助教学, 激发学生学习兴 趣和热情和学习欲望, 由 “要我学” 变为 “我要学”, 提高 课堂教学效果, 使之为教学服务。在教学中, 教师要充分发 挥信息技术的优势, 为学生的学习和发展提供丰富多彩的 教学环境和有力的学习工具, 让中职生感受到学习英语的 动力和鬼力。

\section{[参考文献]}

[1]刘颖,郭伟光,冯超.信息技术与英语教学有效整合的 研究[J].中国轻工教育,2009,(3):48-49.

[2]孙雨.新课程理念下信息技术的定位[J].中小学电 教,2003,(12):78.

[3]黄若好.建构主义与多媒体外语教学模式[J].外语电 化教学,2003,(4):86. 